\title{
Everything Is Relative: A Review of "Minimalism/ Maximalism" at the Museum at FIT
}

\author{
Holly M Lentz Schiller* \\ Stevenson University, USA
}

*Corresponding author: Holly M Lentz Schiller, Associate Professor of Fashion Merchandising, Stevenson University, Owings Mills, MD 21117, USA.

Received Date: June 28, 2019

Published Date: July 02, 2019

\section{Introduction}

Minimalism/Maximalism is currently on exhibit at the Museum at FIT in New York, NY from May 28 until November 16, 2019. The exhibit explores these two dichotomies in both opposition and harmony with the other. Maximalism, according to the exhibit's curator Marra-Alvarez, relies heavily on exaggeration and extreme proportions whereas minimalism operates on a 'less is more' orientation. The time period of pieces included in this exhibit are not limited to a certain epoch, and the pieces are not singularly men's or women's, but span both and incorporate accessories as well.

The exhibit reflects culture and social norms that exist in the sphere of fashion. In particular, the role of the body's relationship with fashion is explored in particular contexts. Minimalism and maximalism are articulated through volume, textiles, surface design, as well as color and construction techniques. Laver's Theory of the Shifting Erogenous Zones comes to mind when walking through the exhibit and viewing the garments from the late seventeenth century, the Jazz Age women's garments, and also work by contemporary designers. Laver's theory contends that the fashion system works as a game of hide and seek, prudery and seduction. For example, the contrast between the early and late 1990's shows a shift from ornamented and fanciful garments, focusing on the legs of the female form to an androgynous minimalism with maxi-dresses that were anything but form-fitting.
Political, economic, and social reflections can be seen in this exhibit. The highly ornate yet restrictive dresses of the mid19th century give way to an expanded wardrobe where minimal, activity-specific garments for women can be seen, as bicycling and tennis became popular near the end of the century. Similarly, the divergence between elaborate design in women's fashion and the minimalism of menswear reflects social norms and an uprooted social structure throughout the twentieth and into the $21^{\text {st }}$ century. Events such as World War I and World War II demand a focus on minimalism, with the period following both wars showcasing a return to a new maximalism, reflecting a changed culture where women's roles were forever changed. The most recent pieces included in the exhibit carry strong references to the past and span both of the exhibit's concepts, with the more contemporary fashion leaning heavily towards maximalism. This exhibit expertly navigates design aesthetics while providing a narrative on social mores, addressing complex topics such as sustainability, equality, sexuality, and progress. A viewer cannot help but wonder what will be next in fashion.

\section{Acknowledgement}

None.

\section{Conflict of Interest}

No conflict of interest. 